Research Article

\title{
An Exploratory Study to Assess the Knowledge and Utilization of First Aid Box in Vehicles for First Aid in Road Traffic Accidents among the Employees at Jamia Hamdard, New Delhi
}

\author{
Saba Hashmi', Asha T Anion ${ }^{2}$ \\ 1,2Tutor, Rufaida College of Nursing, Jamia Hamdard, New Delhi, India. \\ DOI: https://doi.org/10.24321/2455.9318.202030
}

\section{I $\quad \mathbf{N} \quad \mathbf{F} \quad \mathbf{O}$}

Corresponding Author:

Saba Hashmi, Rufaida College of Nursing, Jamia Hamdard, New Delhi, India.

E-mail Id:

softhashmi@yahoo.com

Orcid Id:

https://orcid.org/0000-0001-6321-9753

How to cite this article:

Hashmi S, Anion AT. An Exploratory Study to Assess the Knowledge and Utilization of First Aid Box in Vehicles for First Aid in Road Traffic Accidents among the Employees at Jamia Hamdard, New Delhi. Int J Nurs Midwif Res 2020; 7(4): 18-23.

Date of Submission: 2020-12-16

Date of Acceptance: 2020-12-30

\section{$\begin{array}{llllllllllll}\mathbf{A} & \mathbf{B} & \mathbf{S} & \mathbf{T} & \mathbf{R} & \mathbf{A} & \mathbf{C} & \mathbf{T}\end{array}$}

The trend in road traffic accident injuries and fatality is becoming shocking in countries like India. Delhi is one of the top 5 states in India with highest reported road traffic accidents and injuries. After a road traffic accident, the first few minutes are critical, as measures taken during this time period can be lifesaving.

Methods: The research approach adopted for the study was descriptive approach. The tool developed for the data collection was a structured knowledge questionnaire. Convenient sampling technique was adopted which consisted of 50 people among the employees working in Jamia Hamdard, New Delhi. The analysis was done by computing the frequencies and percentages.

Results: Findings revealed that out of 50 sample (64\%) had average knowledge on first aid in road traffic accidents, whereas $24 \%$ had good knowledge of first aid in road traffic accident and only $12 \%$ had poor knowledge of first aid in road traffic accident. Regarding utilization of first aid box in their vehicles, majority of the employees $(77 \%)$ were found to be having good knowledge of utilization of first aid box in their vehicles. Only $23 \%$ had poor knowledge of utilization of first aid box in their vehicles.

Conclusion: The study showed that majority of the subjects had average knowledge about first aid in road traffic accident and adequate first aid items in their first aid box.

Keywords: Knowledge, Employee, First Aid Box

\section{Introduction}

Road accident is an unfortunate episode that happens unpredictably and inadvertently which causes injuries, damages, loss of life and these accidents are originated because of an involvement of vehicles on an open road. It's estimated that road traffic injuries will move up to the third place by the year 2020 as its contributed great burden on the country. They cause huge economic losses to sufferers, their families, and to countries as an entire. 
It was reported in 2013 that over 231000 people die per annum on road because of road accidents in India. ${ }^{1}$ The bulk of cases of road accidents in India are among people using two-wheelers. Various traffic combine that features fast-speed vehicles sharing the road space with high-risk road users like cyclists and motorcyclists as well as the poor conditions of the road, all contributed to road accidents among Indians.

Delhi is one among the highest 5 states in India with the best reported highway traffic accidents, though many accident causalities in Delhi are not registered. ${ }^{2}$

Providing immediate care is vital to save lots of life. Postponing in providing interventions associated with firstaid and delay in identifying cases of accidents may enhance the severity of injuries and damage. Care of injury after a breakdown has occurred is tremendously important; delays of seconds can make the difference between existence and loss. Recovering from post-break down after an accident depend on timely management and application of first aid to victims.

$40 \%$ of the whole deaths are credited because of excessive loss of blood before getting medical help. The most reason for death of road accident victims is hemorrhage which results in shock. ${ }^{3}$

Everyone has the capability to save lives. First aid teaching and training are essential equipment for saving the lives in emergencies. A primary aid is an act of humanity showing motivation to save lots of lives with the total respect for a range and without favoritism. Building skills during a first aid for the people can help to make safer and healthier communities. ${ }^{4}$

The life-saving first-aid should be a component of a necessary well-being, people above the age of 10 years should get education regarding the life-supporting firstaid and need to develop skills associated with basic lifesupport and emergency procedure.

A review of literature suggested that immediate and appropriate applications of care to victims had decreased the quantity of death cases. Incidence of mortality and disability rate because of road accidents will be minimized by deliberate application of attention to the victims. Timely application of first aid can also prevent disabilities. For these reasons the whole community should be educated and trained in order to obtain knowledge and availability of the first aid kit on their vehicle, in a way so that everybody can practice first aid. ${ }^{3}$

Therefore, investigators felt the need for conducting the study to explore the availability of first aid box in vehicles and find out if the employees know how to utilize the different articles of a vehicle first aid box.

\section{Objectives}

The overall study objective is to:

- To assess the knowledge and utilization of first aid in road traffic accidents

- To explore the vehicles for the availability of first aid box

\section{Methods}

The research approach adopted for the study was descriptive approach. The tool developed for the data collection was a structured knowledge questionnaire. The tool was validated by 10 experts. Convenient sampling was adopted to select sample. The sample consisted of 50 employees from Jamia Hamdard University, New Delhi. The tool was designed in 3 parts: Part A, Part B, and C.

Part A includes 7 items on demographic data such as age, professional, education, religion, marital status, occupation, people ever faced dengue fever. Part B includes 20 knowledge items. All the questions are of MCQ item. Each item has 1 correct response. The score of 1 is awarded for each correct answer. The maximum total score is 20 . Those who scored above 70 were said to have good knowledge and those who scored between $70 \%$ to $50 \%$ considered to have average knowledge, and below $50 \%$ were poor knowledge. The analysis was done by computing the frequencies and percentages. Part C consisted of a structured questionnaire developed by investigators to assess the knowledge on utilization of first aid box in road traffic accidents. It contains 10 multiple choice questions.

\section{Results}

Analysis of the data was done by using descriptive statistics.

\section{Findings Related to Demographic Data}

Table I.Frequency and Percentage Distribution of Sample Subjects by their Demographic Profile (Age, Gender, Qualification, Professional Field of Work, Past Experience Course of Study)

$(\mathrm{N}=50)$

\begin{tabular}{|c|c|c|c|}
\hline \multirow{2}{*}{ S. No. } & Demographic Data & Frequency & Percentage (\%) \\
\hline \multirow{3}{*}{1.} & \multicolumn{3}{|c|}{ Age } \\
\cline { 2 - 4 } & $25-35$ years & 18 & 36 \\
\cline { 2 - 4 } & $36-45$ years & 15 & 30 \\
\hline
\end{tabular}




\begin{tabular}{|c|c|c|c|}
\hline & $46-55$ years & 14 & 28 \\
\hline & Above 56 years & 3 & 6 \\
\hline \multicolumn{4}{|c|}{ Gender } \\
\hline \multirow[t]{2}{*}{2.} & Male & 30 & 60 \\
\hline & Female & 20 & 40 \\
\hline \multirow{5}{*}{3.} & \multicolumn{3}{|c|}{ Qualification } \\
\hline & Graduate & 16 & 32 \\
\hline & Post-graduate & 16 & 32 \\
\hline & Ph.D. & 13 & 26 \\
\hline & Other & 5 & 10 \\
\hline \multirow{3}{*}{4.} & \multicolumn{3}{|c|}{ Field of work } \\
\hline & Medical & 31 & 62 \\
\hline & Non-medical & 19 & 38 \\
\hline \multirow{3}{*}{5.} & \multicolumn{3}{|c|}{ Past experiences with first aid in road traffic accident } \\
\hline & Yes & 14 & 28 \\
\hline & No & 36 & 72 \\
\hline \multirow{3}{*}{6.} & \multicolumn{3}{|c|}{ Witnessed a road traffic accident } \\
\hline & Yes & 29 & 58 \\
\hline & No & 21 & 42 \\
\hline \multirow{3}{*}{7.} & \multicolumn{3}{|c|}{ Suffered a road traffic accident } \\
\hline & Yes & 19 & 38 \\
\hline & No & 31 & 62 \\
\hline \multirow{3}{*}{8.} & \multicolumn{3}{|c|}{ Received training regarding first aid in emergency situations } \\
\hline & Yes & 22 & 44 \\
\hline & No & 28 & 56 \\
\hline
\end{tabular}

Findings Related to Analysis of Knowledge Scores of the Subject

Table 2(a).Frequency and Percentage Distribution of Knowledge Score on First Aid in Road Traffic Accident Among the Employees

\begin{tabular}{|c|c|c|}
\hline Knowledge score of first aid in road traffic accidents & Frequency & Percentage (\%) \\
\hline Poor [<9] & 6 & 12 \\
\hline Average [10-15] & 32 & 64 \\
\hline Good [16-20] & 12 & 24 \\
\hline
\end{tabular}

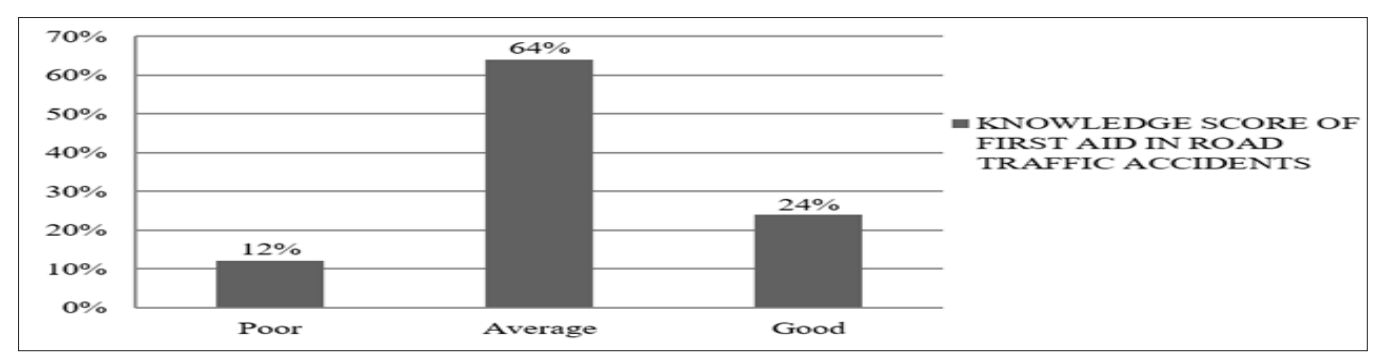

Figure I.Histogram Showing the Percentage Distribution of Knowledge Score of Employees on First Aid in Road Traffic Accidents 
Table 2(b).Mean, Median, Mode and Standard Deviation of Knowledge Score of Employees Regarding First Aid in Road Traffic Accidents

\begin{tabular}{|c|c|c|c|c|c|c|}
\hline Variable & $\begin{array}{c}\text { Possible range of } \\
\text { score }\end{array}$ & $\begin{array}{c}\text { Obtained range of } \\
\text { score }\end{array}$ & Mean & Median & Mode & Standard deviation \\
\hline $\begin{array}{c}\text { Knowledge } \\
\text { score }\end{array}$ & $0-20$ & $0-17$ & 12.96 & 13 & 10 & 3.05 \\
\hline
\end{tabular}

Findings Related to Analysis of Knowledge Scores of Utilizations of First Aid Box in the Vehicles among the Subjects

Table 3(a).Frequency and Percentage Distribution of Knowledge Score on Utilization of First Aid Box in Vehicles Among Employees

\begin{tabular}{|c|c|c|}
\hline $\begin{array}{c}\text { Knowledge score of utilization of first aid box in vehicles } \\
\text { of employees }\end{array}$ & Frequency & Percentage (\%) \\
\hline Poor [<3] & 6 & 23 \\
\hline Average [4-6] & 21 & 42 \\
\hline Good [7-10] & 23 & 46 \\
\hline
\end{tabular}

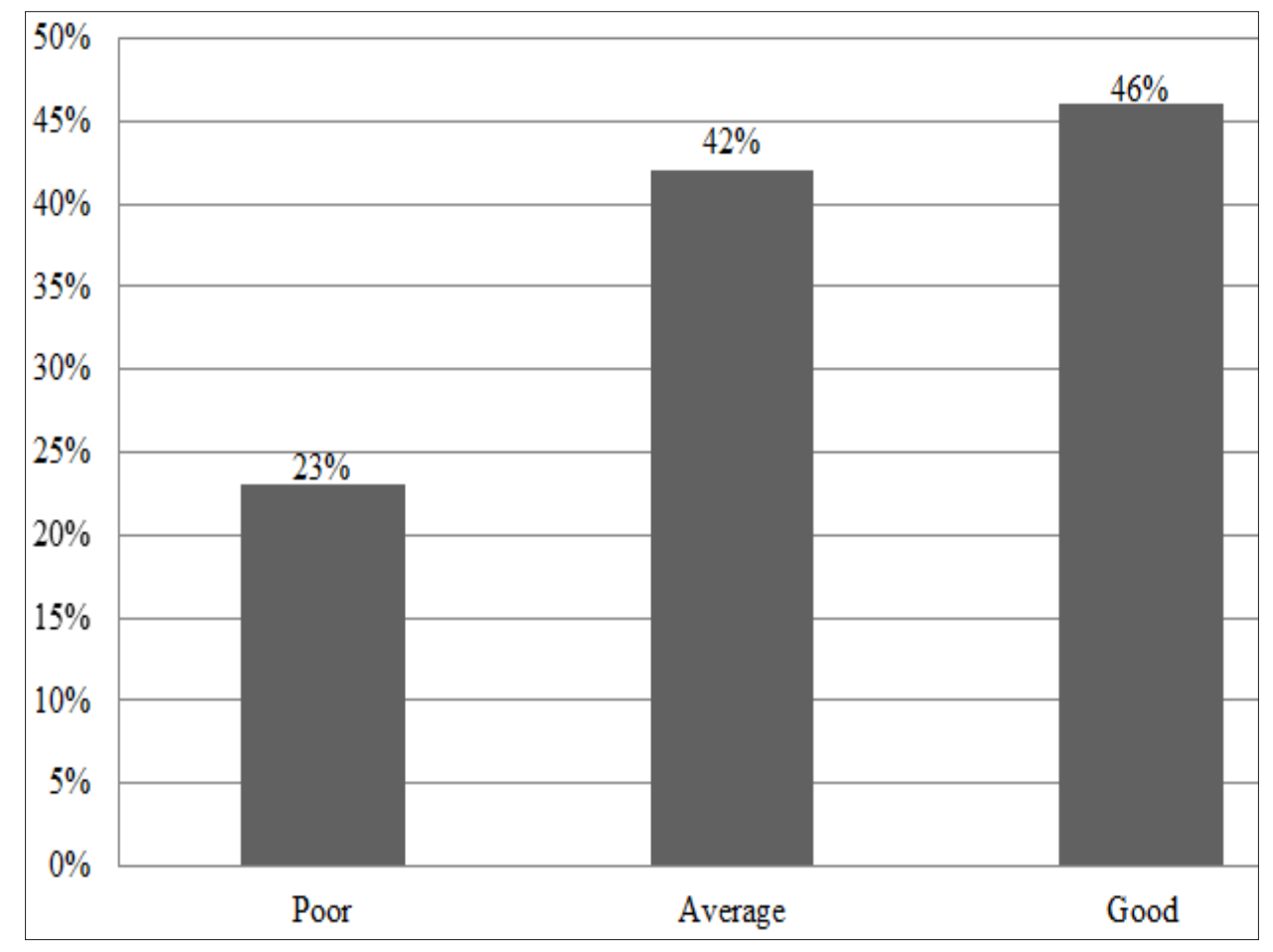

Figure 2.Histogram Showing the Knowledge Score of Utilization of First Aid Box in Vehicles of Employees

Table3(b).Mean, Median, Mode and Standard Deviation of Knowledge Score of Utilization of First Aid Box in Vehicles of the Employees

\begin{tabular}{|c|c|c|c|c|c|c|}
\hline Variable & $\begin{array}{c}\text { Possible range of } \\
\text { score }\end{array}$ & $\begin{array}{c}\text { Obtained range of } \\
\text { score }\end{array}$ & Mean & Median & Mode & Standard deviation \\
\hline Knowledge score & $0-10$ & $0-9$ & 6.04 & 6 & 7 & 1.81 \\
\hline
\end{tabular}




\section{Description on the Availability of First Aid Box in Vehicles of Employees and Adequacy of the First Aid Box}

The data is presented in Table 4 and 5, shows out of 50 sample subjects, $66 \%$ of the employees were found to have a first aid box in their vehicles while $34 \%$ were not having a first aid box in their vehicles. Regarding adequacy of first aid items- $34 \%$ were found to have an adequate first aid items (more than 15 items) in their first aid box while 32\% did not have an adequate first aid items in their first aid box.

Table 4.Frequency and Percentage Distribution in the First Aid Box of Employees - Vehicles

$(\mathrm{N}=50)$

\begin{tabular}{|c|c|c|}
\hline $\begin{array}{c}\text { Availability of first aid } \\
\text { box in vehicles }\end{array}$ & Frequency & Percentage (\%) \\
\hline Yes & 33 & 66 \\
\hline No & 17 & 34 \\
\hline
\end{tabular}

Table 5.Frequency and Percentage Distribution in the First Aid Box of Employees - Vehicles

$(\mathrm{N}=33)$

\begin{tabular}{|c|c|c|}
\hline $\begin{array}{c}\text { Adequacy of first aid } \\
\text { items }\end{array}$ & Frequency & Percentage (\%) \\
\hline Adequate [1-9] & 17 & 34 \\
\hline Inadequate [10-19] & 16 & 32 \\
\hline
\end{tabular}

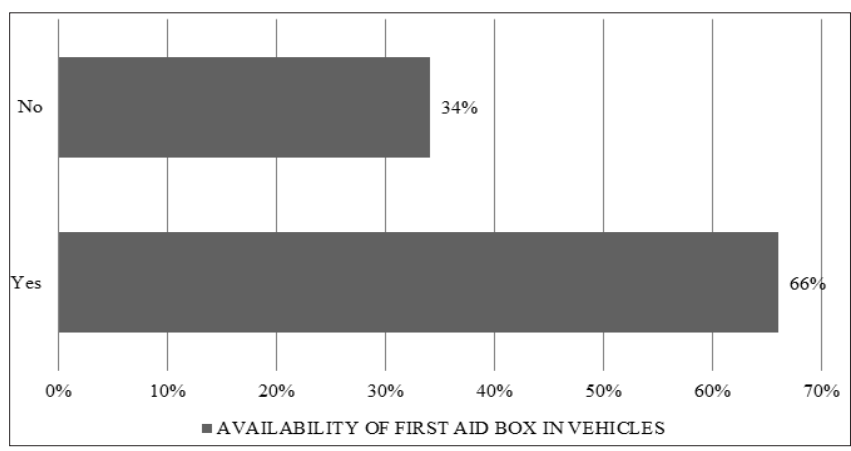

Figure 3.Bar Chart Showing the Availability of First Aid Box in Vehicles of the Employees

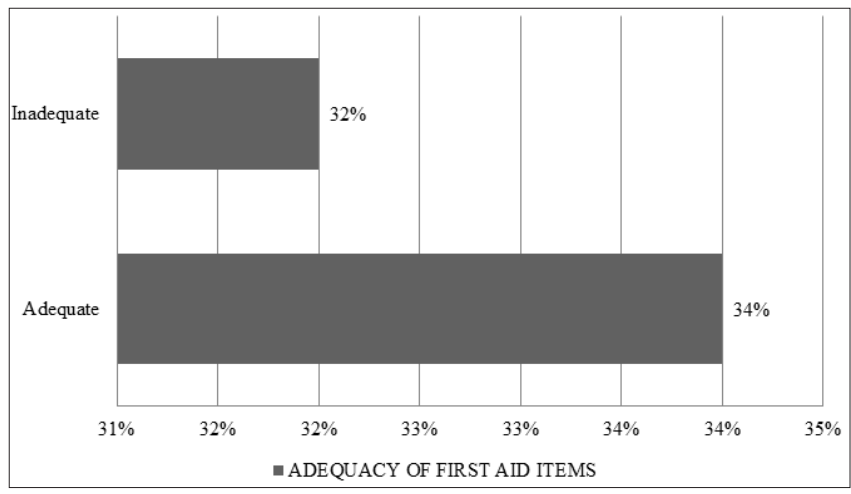

Figure 4.Bar Chart Showing the Adequacy of First Aid Items in First Aid Box of the Employee's Vehicles

\section{Discussion}

The present study was aimed to assess knowledge and utilization of first aid box in vehicles for first aid in road traffic accidents among the employees at Jamia Hamdard, New Delhi.

In the present study the findings revealed that majority of the employees have average knowledge (64\%) on first aid in road traffic accidents, while $24 \%$ have good knowledge; only $12 \%$ have poor knowledge on first aid in road traffic accident.

The present study also showed that majority of the employees (77\%) were found to be having good knowledge of utilization of first aid box in their vehicles and $23 \%$ have poor knowledge of utilization of first aid boxes in their vehicles. $66 \%$ of the employees were found to have a first aid box in their vehicles while $34 \%$ were not having a first aid box in their vehicles. Out of the $66 \%$, only $34 \%$ were found to have adequate first aid items in their first aid box while $32 \%$ did not have adequate first aid items in their first aid box.

The study findings are consistent with a similar study conducted by Kaur N, Savitri, Kaur M (2017) ${ }^{5}$ to assess the knowledge on First Aid Management among school teachers in selected schools of district Mohali, Punjab. A convenient sampling was used for the study and 40 employees participated in the survey. The results of the study showed that most of the teachers (77\%) were having average knowledge regarding First Aid Management and $23 \%$ were found to have poor knowledge.

Another study conducted by Deepak M, Sabitha Nayak $(2012)^{6}$ to assess the knowledge on first aid measures among self-help group member in selected community areas of Natekal PHC shows similar results. A purposive sampling technique was used and majority of the samples were within the age bracket of $25-30$ years. The findings of study were that $62 \%$ of participants had good knowledge, and $38 \%$ had average knowledge about the First-aid practice.

The study concluded that $65.7 \%$ of students didn't have first aid knowledge and skills earlier. Majority of the students $(98.5 \%)$ felt that it was essential to have first aid education. It was recommended in the study that there is a need of people participation in controlling and managing accidents by improving knowledge and awareness as people with a higher education are more likely to have concern and knowledge.

\section{Conclusion}

The present study concluded that the majority of the employees have average knowledge of first aid in road traffic accidents. There is a need of people participation in controlling and managing accidents by improving knowledge 
and awareness as people with a higher education are more likely to have concern and knowledge.

\section{Acknowledgement}

We take the opportunity to place on records the hard work and the tireless efforts in data collection and compilation of the thesis of B.Sc. Nursing students Batch 2019-2020 of Rufaida College of Nursing, Jamia Hamdard namely Ms. Marufa Khan, Onwuzurike Regina O. Md. Alamgir. Mantasha, Rifa, Mr. Mervin Massey.

\section{Source of Funding: None \\ Conflicts of Interest: None \\ References}

1. World Health Organization. Road Traffic injuries, 2021.

2. http://www.morth.nic.in/government of india ministry of road transport \& highways transport/2014

3. Metin I, Mutlu C. Level of knowledge about first aid of the University students. Trakia J Sci 2010; 8: 262-5.

4. First Aid. Available from: http://www.uni-sz.bg.St John Ambulance Australia. First aid for road users and online first aid crash course. WA Ambulance Service Inc., 2006.

5. Kaur N, Savitri, Kaur M. Descriptive Study to Assess the Level of Knowledge Regarding the First Aid Management among School Teachers in Selected Schools of District Mohali, Punjab. $8^{\text {th }}$ edition. J Health Med Informat 2017; 8(4).

6. Deepak M, NayakS. A study on assessment of knowledge on practice regarding first aid measures among the self help groups in selected areas of Mangalore with a view to develop information module. Nittie Univ J Health Sci 2012; 2(3). 